\title{
Evaluation of Amphotericin B Lipid Formulations for Treatment of Severe Coccidioidomycosis
}

\author{
Ritam Sidhu, a (D)David B. Lash, ${ }^{b}$ Arash Heidari,c (DPiruthiviraj Natarajan, a Royce H. Johnsonc \\ aDepartment of Medicine, Kern Medical/UCLA, Bakersfield, California, USA \\ bDepartment of Pharmacy, Kern Medical, Bakersfield, California, USA \\ 'Department of Infectious Diseases, Kern Medical/UCLA, Bakersfield, California, USA
}

ABSTRACT Patients with severe coccidioidomycosis infections are often treated with either amphotericin B lipid complex (ABLC) or liposomal amphotericin B (L$A m B)$. Outcome data with these agents in severe coccidioidomycosis cases are currently lacking. The purpose of this study is to evaluate the efficacy and toxicity of $A B L C$ and L-AmB in treating severe coccidioidomycosis. A retrospective pre-post study design was employed. Chart reviews were completed from 1 January 2005 to 31 December 2014 for all patients who received lipid-based amphotericin B. Inclusion criteria included having a follow-up complement fixation (CF) titer or a treatment emergent adverse event (TEAE) prior to follow-up. Patients with meningeal involvement and pregnant patients were excluded. Treatment outcomes were assessed based on documented completion of therapy as well on symptoms, complement fixation titer, and changes to laboratory monitoring parameters. A total of 108 patients were identified, 69 of whom met the inclusion criteria. There were no statistical differences in demographics or disease burden in those that received ABLC and those that received $L-A m B$, except that those who received $L-A m B$ were more likely to have previously diagnosed chronic kidney disease $\left(n_{\mathrm{L}-\mathrm{AmB}}=4,12.5 \%\right.$ vs $n_{\mathrm{ABLC}}=0$, $0.0 \% ; P=0.042$ ) and to have a lower creatinine clearance at the start of therapy (L$\mathrm{AmB}=79.6 \mathrm{mg} / \mathrm{dl}$ versus $\mathrm{ABLC}=100.4 \mathrm{mg} / \mathrm{dl} ; P=0.008)$. Successful treatment was achieved in $27(73.0 \%)$ of ABLC patients and $22(68.8 \%)$ of L-AmB patients $(P=$ 0.700). Amphotericin $B$ was discontinued due to documented completion of therapy for 17 (45.9\%) ABLC patients and 18 (56.3\%) L-AmB patients $(P=0.553)$. Acute kidney injury $(\mathrm{AKI})$ was the documented reason of treatment cessation for $10(27.0 \%)$ ABLC and 1 (3.1\%) L-AmB patient $(P=0.007)$. ABLC and L-AmB both appear to be equally efficacious in the treatment of severe coccidioidomycosis. L-AmB may have less renal toxicity than $A B L C$ and may be the preferred agent in baseline renal impairment.

KEYWORDS coccidioidomycosis, amphotericin B, AmBisome, Abelcet, treatment

occidioidomycosis is a reemerging infectious disease that is predominantly caused

by Coccidioides immitis in California and by Coccidioides posadasii in Arizona (1). The disease is contracted through inhalation of Coccidioides spp. spores, which germinate in the lungs, forming mature spherules that can avoid phagocytosis due to their size (2-4). Of those infected, $60 \%$ will be asymptomatic, $40 \%$ will develop mild-tomoderate influenza-like illness, and less than $1 \%$ will develop extrapulmonary disease (5-7). Within California, coccidioidomycosis is most prevalent in the San Joaquin Valley, and the disease is endemic to the southwestern United States, Mexico, and Central and South America (3). Hospitalization rates due to coccidioidomycosis in California have increased from 2.3 initial hospitalizations per 100,000 person-years in 2000 to 5.0 initial hospitalizations per 100,000 person-years in 2011. The 2011 infection rate is consider-
Received 25 November 2017 Returned for modification 1 March 2018 Accepted 7 April 2018

Accepted manuscript posted online 23 April 2018

Citation Sidhu R, Lash DB, Heidari A, Natarajan P, Johnson RH. 2018. Evaluation of amphotericin B lipid formulations for treatment of severe coccidioidomycosis. Antimicrob Agents Chemother 62:e02293-17. https://doi .org/10.1128/AAC.02293-17.

Copyright $\odot 2018$ American Society for Microbiology. All Rights Reserved. Address correspondence to Arash Heidari, ArashHeidari@yahoo.com, or Royce H. Johnson, RoyceJohnson@KernMedical.com. 
ably higher in regions of California where coccidioidomycosis is more endemic, such as Kern County (61.9 initial hospitalizations/100,000 person-years) and Kings County (63.5 initial hospitalizations/100,000 person-years) $(3,8,9)$.

Treatment of coccidioidomycosis typically involves oral triazole derivatives in less severe cases and intravenous amphotericin B in severe cases. Meningeal coccidioidomycosis may require intrathecal amphotericin $B(1,10,11)$. Assessment of treatment progress is often difficult to quantify, due to the varied course of the disease. A composite scoring system based on symptoms, physical examination, complement fixation (CF) titers, and culture results, known as the Mycosis Study Group (MSG) score is the recommended modality for assessing therapeutic response, with success being defined as a $50 \%$ or greater reduction in MSG score from baseline at eight or fewer months $(1,12)$. Even though amphotericin B is reputed to be the gold standard in acute, severe coccidioidomycosis, studies investigating the better-tolerated lipid formulations of amphotericin $B$ in the disease are not adequate and are limited to murine and rabbit models and a few case studies (13-18).

Lipid-based amphotericin B is commonly available as two formulations in the United States, amphotericin B lipid complex (ABLC) (Abelcet) and liposomal amphotericin B ( $\mathrm{L}-\mathrm{AmB}$ ) (AmBisome). There have been few prospective randomized controlled trials that directly compared ABLC with L-AmB (19). These lipid formulations, along with the conventional deoxycholate form, are generally considered to be equally efficacious, as supported by comparative studies on the empirical treatment of neutropenic fever patients and on the treatment of invasive fungal infections in immunocompromised patients $(20,21)$. There is some disagreement in the literature regarding the toxicities of the three amphotericin B agents. Conventional amphotericin B is associated with the greatest amount of nephrotoxicity and poorest tolerability of all amphotericin B formulations (21). Wingard et al. were the first to show that L-AmB causes less nephrotoxicity than $A B L C$, but a subsequent meta-analysis suggested that the rates of nephrotoxicity are generally similar between the two agents (20-24). In addition to nephrotoxicity, amphotericin B has been associated with hepatotoxicity, which occasionally results in discontinuation of therapy (25).

The purpose of this study is to describe the efficacy and toxicity of lipid-based amphotericin B in the treatment of severe coccidioidomycosis, as well as to investigate differences between the two lipid-based formulations.

\section{RESULTS}

A total of 108 patients were identified as having received lipid-based amphotericin $B$ on an outpatient basis for the treatment of coccidioidomycosis. Ten patients were excluded due to the lack of baseline records, 13 were lost prior to follow-up assessment, and 16 patients were pregnant. Sixty-nine patients met inclusion/exclusion criteria and were included in the primary analysis.

Patient demographics are described in Table 1 and show no significant differences between the ABLC and L-AmB groups. The study population was predominantly male $\left(n=53,76.8 \% ; n_{\mathrm{ABLC}}=30,81.1 \%\right.$ versus $\left.n_{\mathrm{L}-\mathrm{AmB}}=23,71.9 \% ; P=0.817\right)$. The median age was 37 years old (ABLC $=41$ years versus $L-A m B=34.5$ years; $P=0.753$ ). Nearly half ( $n=34,49.3 \%$ ) of the study population were identified as nonwhite Hispanic and almost a third ( $n=21,30.4 \%$ ) were black or African-American; there was no statistically significant difference in terms of ethnicity between the ABLC and L-AmB groups $(P=$ 0.766). The population was otherwise relatively healthy, with only 26 total patients (37.7\%) having any comorbid condition $\left(n_{\mathrm{ABLC}}=13,35.1 \%\right.$ versus $n_{\mathrm{L}-\mathrm{AmB}}=13,40.6 \%$; $P=0.639)$. There was one statistically significant difference between the lipid-based amphotericin B groups, as those who were diagnosed with baseline chronic kidney disease $(n=4)$ exclusively received L-AmB $(P=0.042)$.

Table 2 and Table 3 summarize severity of coccidioidomycosis disease at the initiation and cessation of therapy, respectively. Patients had active disease in multiple organ systems ( $n=38,55.1 \% ; n_{\mathrm{ABLC}}=20,54.1 \%$ versus $n_{\mathrm{L}-\mathrm{AmB}}=18,56.3 \% ; P=0.513$ ). Dissemination of coccidioidomycosis to the skeletal system was also present in over 
TABLE 1 Demographics

\begin{tabular}{|c|c|c|c|c|}
\hline \multirow[b]{2}{*}{ Variable $^{a}$} & \multicolumn{3}{|l|}{ Treatment } & \multirow[b]{2}{*}{$P$ value } \\
\hline & Combined & $\begin{array}{l}\text { Amphotericin B } \\
\text { lipid complex }\end{array}$ & $\begin{array}{l}\text { Liposomal } \\
\text { amphotericin B }\end{array}$ & \\
\hline No. of subjects & 69 & 37 & 32 & 0.547 \\
\hline Age in yrs (median [IQR]) & $37(28-45)$ & $41(28-44)$ & $34.5(27.75-45.25)$ & 0.753 \\
\hline No. of males (\%) & $53(76.8)$ & $30(81.1)$ & $23(71.9)$ & 0.817 \\
\hline \multicolumn{5}{|l|}{ Ethnicity ( $n$ [\%]) } \\
\hline White & $8(11.6)$ & $3(8.1)$ & $5(15.6)$ & 0.766 \\
\hline Hispanic nonwhite & $34(49.3)$ & $20(54.1)$ & $14(43.8)$ & \\
\hline Black & $21(30.4)$ & $10(27.0)$ & $11(34.4)$ & \\
\hline Asian & $3(4.3)$ & $2(5.4)$ & $1(3.1)$ & \\
\hline Other & $3(4.3)$ & $2(5.4)$ & $1(3.1)$ & \\
\hline \multicolumn{5}{|c|}{ Preexisting conditions ( $n[\%]$ ) } \\
\hline Any & $26(37.7)$ & $13(35.1)$ & $13(40.6)$ & 0.639 \\
\hline DM & $20(29.0)$ & $13(35.1)$ & $7(21.9)$ & 0.226 \\
\hline CKD & $4(5.8)$ & $0(0.0)$ & $4(12.5)$ & 0.042 \\
\hline Malignancy & $2(2.9)$ & $2(5.4)$ & $0(0.0)$ & 0.495 \\
\hline Corticosteroid & $1(1.4)$ & $1(2.7)$ & $0(0.0)$ & 1.000 \\
\hline HIV/AIDS & $6(8.7)$ & $3(8.1)$ & $3(9.4)$ & 1.000 \\
\hline Pulmonary TB & $1(1.4)$ & $1(2.7)$ & $0(0.0)$ & 1.000 \\
\hline Anemia & $2(2.9)$ & $0(0.0)$ & $2(6.3)$ & 0.211 \\
\hline COPD/asthma & $6(8.7)$ & $3(8.1)$ & $3(9.4)$ & 1.000 \\
\hline Hepatitis & $4(5.8)$ & $2(5.4)$ & $2(6.3)$ & 1.000 \\
\hline $\mathrm{CAD} / \mathrm{CHF}$ & $8(11.6)$ & $3(8.1)$ & $5(15.6)$ & 0.457 \\
\hline
\end{tabular}

${ }^{a} \mathrm{IQR}$, interquartile range; CKD, chronic kidney disease; TB, tuberculosis; COPD, chronic obstructive pulmonary disease; $\mathrm{CAD} / \mathrm{CHF}$, coronary artery disease/congestive heart failure.

half of the study population ( $n=39,56.5 \% ; n_{\mathrm{ABLC}}=19,51.4 \%$ versus $n_{\mathrm{L}-\mathrm{AmB}}=20$, $62.5 \% ; P=0.352$ ). Sputum or tissue cultures were positive for Coccidioides immitis in $30(43.5 \%)$ patients $\left(n_{\mathrm{ABLC}}=16,43.2 \%\right.$ versus $\left.n_{\mathrm{L}-\mathrm{AmB}}=14,43.8 \% ; P=0.966\right)$. Complement fixation antibody titer was greater than or equal to 1:64 (the maximum serial-dilution category in the MSG score) in $49(71.0 \%)$ patients ( $n_{\text {ABLC }}=26,70.3 \%$ versus $\left.n_{\mathrm{L}-\mathrm{AmB}}=23,71.9 \% ; P=0.348\right)$. There were no statistically significant differences in symptoms (e.g., cough, fever, myalgia, etc.) at presentation (data not shown) or in number of symptoms at presentation (median $_{\mathrm{ABLC}}=4$ versus median $_{\mathrm{L}-\mathrm{AmB}}=$ 5; $P=0.219)$.

Modified MSG (mMSG) scores showed significant improvement from beginning of therapy to end $\left(\mathrm{mMSG}_{\text {StartAll }}=7, \mathrm{mMSG}_{\text {EndAll }}=3, P<0.001 ; \mathrm{mMSG}_{\text {StartABLC }}=7\right.$, $\mathrm{mMSG}_{\text {EndABLC }}=3, P<0.001 ; \mathrm{mMSG}_{\text {StartL-AmB }}=7, \mathrm{mMSG}_{\text {EndL-AmB }}=3, P<0.001$ ). Although starting $\mathrm{mMSG}$ scores were numerically larger in the group that received liposomal amphotericin B (median, 7; interquartile range [IQR], 5 to 9.25) compared to those in the group that received amphotericin-B lipid complex (median, 7; IQR, 4 to 8), there were no statistically significant differences between the two groups at start $(P=$ $0.119)$ or end $(P=0.549)$ of therapy. Predefined success of therapy was met in 49 (71.0\%) patients, and there was no statistically significant difference between groups $\left(n_{\mathrm{ABLC}}=27,73.0 \%\right.$ versus $\left.n_{\mathrm{L}-\mathrm{AmB}}=22,68.8 \% ; P=0.700\right)$.

Routinely monitored laboratory tests are shown in Table 4 with starting and ending laboratory values, as well as a follow-up creatinine clearance. Statistical tests were completed both between and within groups at start and end of therapy. There were no statistically significant changes in common liver/biliary function tests, such as aspartate transaminase (AST), alanine transaminase (ALT), alkaline phosphatase (AlkPhos), and total bilirubin (Tbili) between the two amphotericin $B$ products or from start to end of therapy, with the exception that the L-AmB group showed a significant improvement in AST from start of therapy to end (52.2 units/liter versus 19.2 units/liter, respectively; $P<0.001)$. Both ABLC and L-AmB patients showed a decrease in platelets from start of therapy to end, but no thrombocytopenia (defined as a platelet count of less than $150 \times 10^{3} / \mu \mathrm{l}$ ) was observed. Males and females within the ABLC group had a modest 
TABLE 2 Disease burden at start of therapy

\begin{tabular}{|c|c|c|c|c|}
\hline \multirow[b]{2}{*}{ Variable } & \multicolumn{3}{|l|}{ Treatment } & \multirow[b]{2}{*}{$P$ value } \\
\hline & Combined & $\begin{array}{l}\text { Amphotericin B } \\
\text { lipid complex }\end{array}$ & $\begin{array}{l}\text { Liposomal } \\
\text { amphotericin B }\end{array}$ & \\
\hline Active disease sites ( $n$ [\%]) & 69 & 37 & 32 & \\
\hline Pulmonary & $54(78.2)$ & $30(81.1)$ & $24(75.0)$ & 0.541 \\
\hline Cutaneous & $9(13.0)$ & $3(8.1)$ & $6(18.8)$ & 0.285 \\
\hline Soft tissue & $19(27.5)$ & $11(29.7)$ & $8(25.0)$ & 0.661 \\
\hline Lymph & $4(5.8)$ & $2(5.4)$ & $2(6.3)$ & 1.000 \\
\hline Osseous & $39(56.5)$ & $19(51.4)$ & $20(62.5)$ & 0.352 \\
\hline \multicolumn{5}{|l|}{ No. of active disease sites ( $n[\%]$ ) } \\
\hline 1 & $31(44.9)$ & $17(45.9)$ & $14(43.8)$ & 0.513 \\
\hline 2 & $15(21.7)$ & $7(18.9)$ & $8(25.0)$ & \\
\hline 3 & $13(18.8)$ & $9(24.3)$ & $4(12.5)$ & \\
\hline 4 & $10(14.5)$ & $4(10.8)$ & $6(18.8)$ & \\
\hline \multicolumn{5}{|l|}{ Symptoms ${ }^{a}$} \\
\hline Total at presentation (median [IQR]) & $5(2-6)$ & $4(2-6)$ & $5(3-7)$ & 0.219 \\
\hline Positive C. immitis culture ( $n[\%]$ ) & $30(43.5)$ & $16(43.2)$ & $14(43.8)$ & 0.966 \\
\hline \multicolumn{5}{|l|}{ CF antibody titer } \\
\hline $\begin{array}{l}\text { MSG CF antibody titer score } \\
\text { (median [IQR]) }\end{array}$ & $3(2-3)$ & $3(2-3)$ & $3(2-3)$ & 0.803 \\
\hline \multicolumn{5}{|l|}{ MSG CF antibody titers ( $n$ [\%]) } \\
\hline$\leq 1: 2$ & $6(8.7)$ & $5(13.5)$ & $1(3.1)$ & 0.348 \\
\hline $1: 4$ or $1: 8$ & $4(5.8)$ & $1(2.7)$ & $3(9.4)$ & \\
\hline $1: 16$ or $1: 32$ & $10(14.5)$ & $5(13.5)$ & $5(15.6)$ & \\
\hline$\geq 1: 64$ & $49(71.0)$ & $26(70.3)$ & $23(71.9)$ & \\
\hline Starting mMSG Score (median [IQR]) & $7(5-9)$ & $7(4-8)$ & $7(5-9.25)$ & 0.119 \\
\hline
\end{tabular}

aThere were no significant differences between specific symptoms at presentation.

decrease in hemoglobin. At baseline, the ABLC group had a lower serum creatinine (0.88 $\mathrm{mg} / \mathrm{dl}$ versus $1.11 \mathrm{mg} / \mathrm{dl}$, respectively, $P=0.028$ ) and corresponding higher creatinine clearance than the L-AmB group $(100.4 \mathrm{ml} / \mathrm{min}$ versus $79.6 \mathrm{ml} / \mathrm{min}$, respectively; $P=0.008)$, but this difference was not seen at the end of therapy $(P=0.902$ and $P=0.498$, respectively). Both groups had a statistically significant increase in serum creatinine $\left(\mathrm{SCR}\right.$ ) (starting $\mathrm{SCR}_{\mathrm{ABLC}}=0.88 \mathrm{mg} / \mathrm{dl}$, ending $\mathrm{SCR}_{\mathrm{ABLC}}=1.49, P<0.001$; starting $\mathrm{SCR}_{\mathrm{L}-\mathrm{AmB}}=1.11$, ending $\left.\mathrm{SCR}_{\mathrm{L}-\mathrm{AmB}}=1.51, P<0.05\right)$ and decrease in creatinine clearance $(\mathrm{CrCl})\left(\right.$ starting $\mathrm{CrCl}_{\mathrm{ABLC}}=100.4 \mathrm{ml} / \mathrm{min}$, ending $\mathrm{CrCl}_{\mathrm{ABLC}}=63.3 \mathrm{ml} / \mathrm{min}, P<$ 0.001 ; starting $\mathrm{CrCl}_{\mathrm{L}-\mathrm{AmB}}=79.6 \mathrm{ml} / \mathrm{min}$, ending $\mathrm{CrCl}_{\mathrm{L}-\mathrm{AmB}}=58.7 \mathrm{ml} / \mathrm{min}, P<0.001$ ) from start to end of therapy.

Follow-up of study subjects' renal function is shown in Table 5. Patients who received $A B L C$ displayed a small, but statistically significant, change in renal function from baseline to follow-up (Start $\mathrm{SCR}_{\mathrm{ABLC}}=0.86$, end $\mathrm{SCR}_{\mathrm{ABLC}}=1.01, P=0.009$; start $\mathrm{CrCl}_{\mathrm{ABLC}}=102.4 \mathrm{ml} / \mathrm{min}$, end $\left.\mathrm{CrCl}_{\mathrm{ABLC}}=86.3 \mathrm{ml} / \mathrm{min}, P=0.001\right)$. This change in renal function was not seen in L-AmB patients (start $\mathrm{SCR}_{\mathrm{L}-\mathrm{AmB}}=1.20$, end $\mathrm{SCR}_{\mathrm{L}-\mathrm{AmB}}=1.25$, $P=0.760$; start $\mathrm{CrCl}_{\mathrm{L}-\mathrm{AmB}}=77.3 \mathrm{ml} / \mathrm{min}$, end $\mathrm{CrCl}_{\mathrm{L}-\mathrm{AmB}}=77.1 \mathrm{ml} / \mathrm{min}, P=0.969$ ). Reason for drug discontinuation (Table 6) was analyzed for the 69 patients, 5 of whom switched amphotericin formulations during treatment. Therapy was stopped early in a total of $33(47.8 \%)$ patients (ABLC $=19,51.4 \%$; L-AmB $=14,43.8 \%)$, but only $5(7.2 \%)$ patients were deemed to have failed therapy $\left(n_{\mathrm{ABLC}}=1, n_{\mathrm{L}-\mathrm{AmB}}=4 ; P=0.117\right)$, including 2 deaths (both treated with L-AmB). Only $4(5.8 \%)$ patients were unable to tolerate lipid-based amphotericin B therapy $\left(n_{\mathrm{ABLC}}=3, n_{\mathrm{L}-\mathrm{AmB}}=1 ; P=0.377\right)$. Acute kidney injury was documented in 10 (27\%) ABLC patients compared to 1 (3.1\%) L-AmB patient $(P=0.007)$.

\section{DISCUSSION}

This is the first study that has investigated lipid-based amphotericin B use in severe coccidioidomycosis, and it is also the first study to compare the two lipid-based 
TABLE 3 Disease burden at end of therapy

\begin{tabular}{|c|c|c|c|c|}
\hline \multirow[b]{2}{*}{ Variable } & \multicolumn{3}{|l|}{ Treatment } & \multirow[b]{2}{*}{$P$ value } \\
\hline & Combined & $\begin{array}{l}\text { Amphotericin B } \\
\text { lipid complex }\end{array}$ & $\begin{array}{l}\text { Liposomal } \\
\text { amphotericin B }\end{array}$ & \\
\hline $\begin{array}{l}\text { Treatment duration in weeks } \\
\text { (median [IQR]) }\end{array}$ & $7(16-24)$ & $16(6-23)$ & $16.5(10-24.25)$ & 0.337 \\
\hline \multicolumn{5}{|l|}{ Symptoms ${ }^{a}$} \\
\hline $\begin{array}{l}\text { Total at end of therapy } \\
\text { (median [IQR]) }\end{array}$ & $0(0-1)$ & $0.5(0-1)$ & $0(0-2)$ & 0.889 \\
\hline \multicolumn{5}{|l|}{ CF antibody titer } \\
\hline $\begin{array}{l}\text { MSG CF antibody titer score } \\
\text { (median [IQR]) } \\
\text { MSG CF antibody titers ( } n \text { [\%]) }\end{array}$ & $3(2-3)$ & $2(2-3)$ & $3(2-3)$ & 0.246 \\
\hline$\leq 1: 2$ & $3(4.3)$ & $2(5.4)$ & $1(3.1)$ & 0.630 \\
\hline $1: 4$ or $1: 8$ & $4(5.8)$ & $1(2.7)$ & $3(9.4)$ & \\
\hline $1: 16$ or $1: 32$ & $13(18.8)$ & $8(21.6)$ & $5(15.6)$ & \\
\hline$\geq 1: 64$ & $49(71.0)$ & $26(70.3)$ & $23(71.9)$ & \\
\hline Ending mMSG score & 2.9 & 2.7 & 3.2 & 0.212 \\
\hline $\begin{array}{l}\text { Ending mMSG score (median } \\
\qquad[\mathrm{IQR}])\end{array}$ & $3(2-4)$ & $3(2-4)$ & $3(2-4)$ & 0.549 \\
\hline mMSG Decrease of $\geq 50 \%$ & $49(71.0)$ & $27(73.0)$ & $22(68.8)$ & 0.700 \\
\hline
\end{tabular}

aThere were no significant differences between specific symptoms at presentation.

formulations in these patients. Despite our inability to use the Mycosis Study Group score in this retrospective study, the combination of the modified score and physician assessment allow for an accurate assessment of therapy. Overall, 35 (50.7\%) patients were determined to have successfully completed the amphotericin B therapy, and 49 of the 69 patients (71.0\%) achieved a $50 \%$ or greater decrease in our cumulative score of symptoms and CF titer. The efficacy data combined with the few treatment failures ( $n=5 ; 7.2 \%$ ) suggest that lipid-based amphotericin B is highly effective for the treatment of severe coccidioidomycosis. Although the starting and ending mMSG scores were numerically larger in the liposomal amphotericin B group, both groups had similar rates of documented completion. Both amphotericin B lipid complex and liposomal amphotericin B appear to be equally efficacious in the treatment of coccidioidomycosis as has been suggested in other disease states $(20,22,24)$.

Both lipid formulations have been documented as causing infusion reactions (chills, fever, nausea, vomiting, etc.) in upwards of $80 \%$ of patients, with the liposomal formulation causing significantly fewer reactions compared to the lipid complex formulation $(20,22)$. Our study found lipid-based amphotericin B to be well tolerated, as only $4(5.8 \%)$ patients stopped therapy due to intolerance; however, data regarding the frequency of minor infusion reactions, such as fever and chills was not available and all patients received prophylaxis as part of a standardized order set. These data suggest that infusion reactions are not a major cause of discontinuation. Treatment burden, in the form of thrice-weekly, half-day visits to the infusion clinic, appears to be the greatest contributor to early cessation of therapy as $3(4.3 \%)$ patients explicitly stated so to their prescribing physician and $10(14.5 \%)$ patients were noncompliant with regularly thrice-weekly treatment. Quality of life outcomes would be useful in helping to evaluate the differences between ABLC and L-AmB treatment.

The L-AmB group had greater renal insufficiency $(P=0.008)$ and higher rates of documented chronic kidney disease $(P=0.042)$ compared to those of the ABLC group at baseline, but acute kidney injury occurred less often in the L-AmB group compared to the ABLC group ( $P=0.007)$. Because of the incidence of $A K I, A B L C$ therapy was either stopped or suspended more often. This difference in nephrotoxicity was comparable to the study by Wingard et al. that was not observed in the most recent meta-analyses (22, 25). While the effect of amphotericin $B$ on kidney function is believed to be reversible, we found that a small change in serum creatinine $(P=0.009)$ and creatinine clearance 
TABLE 4 Metabolic Laboratory Data

\begin{tabular}{|c|c|c|c|c|}
\hline \multirow[b]{2}{*}{ Assay $^{a}$} & \multicolumn{3}{|l|}{ Treatment } & \multirow[b]{2}{*}{$P$ value } \\
\hline & Combined & $\begin{array}{l}\text { Amphotericin B } \\
\text { lipid complex }\end{array}$ & $\begin{array}{l}\text { Liposomal } \\
\text { amphotericin B }\end{array}$ & \\
\hline \multicolumn{5}{|l|}{ ALT (U/liter) } \\
\hline Starting & 45.8 & 36.3 & 56.8 & 0.151 \\
\hline Ending & 37.5 & 40.4 & 34.1 & 0.432 \\
\hline \multicolumn{5}{|l|}{ AlkPhos (U/liter) } \\
\hline Starting & 134.4 & 128.7 & 141.0 & 0.617 \\
\hline Ending & 143.6 & 136.8 & 151.6 & 0.500 \\
\hline \multicolumn{5}{|l|}{ AST (U/liter) } \\
\hline Starting & 38.7 & 27.0 & $52.2^{b}$ & 0.092 \\
\hline Ending & 21.7 & 23.9 & $19.2^{b}$ & 0.206 \\
\hline \multicolumn{5}{|l|}{$\begin{array}{l}\text { Serum creatinine } \\
(\mathrm{mg} / \mathrm{dl})\end{array}$} \\
\hline Starting & 0.99 & $0.88^{c}$ & $1.11^{b}$ & 0.028 \\
\hline Ending & 1.50 & $1.49^{c}$ & $1.51^{b}$ & 0.902 \\
\hline \multicolumn{5}{|l|}{$\mathrm{CrlCl}(\mathrm{ml} / \mathrm{min})$} \\
\hline Starting & 91.2 & $100.4^{c}$ & $79.6^{c}$ & 0.008 \\
\hline Ending & 61.2 & $63.3^{c}$ & $58.7^{c}$ & 0.498 \\
\hline \multicolumn{5}{|l|}{$\mathrm{HgB}(\mathrm{g} / \mathrm{dl})$} \\
\hline Starting $\mathrm{HgB}_{\text {males }}$ & 11.3 & $11.6^{b}$ & 11.1 & 0.437 \\
\hline Ending $\mathrm{HgB}_{\text {males }}$ & 10.8 & $10.7^{b}$ & 10.8 & 0.920 \\
\hline Starting $\mathrm{HgB}_{\text {females }}$ & 11.2 & $11.8^{b}$ & 10.6 & 0.157 \\
\hline Ending $\mathrm{HgB}_{\text {females }}$ & 10.1 & $9.8^{b}$ & 10.4 & 0.408 \\
\hline \multicolumn{5}{|l|}{$\mathrm{Mg}(\mathrm{mg} / \mathrm{dl})$} \\
\hline Starting & 1.8 & 1.8 & 1.8 & 0.927 \\
\hline Ending & 1.8 & 1.9 & 1.8 & 0.111 \\
\hline \multicolumn{5}{|l|}{ Plt $\left(1 \times 10^{3} / \mu \mathrm{l}\right)$} \\
\hline Starting & 372.0 & $357.8^{c}$ & $388.5^{c}$ & 0.338 \\
\hline Ending & 292.2 & $289.3^{c}$ & $295.5^{c}$ & 0.811 \\
\hline \multicolumn{5}{|l|}{$\mathrm{K}$ (mEq/liter) } \\
\hline Starting & 3.9 & 3.9 & 3.8 & 0.552 \\
\hline Ending & 3.9 & 4.0 & 3.8 & 0.058 \\
\hline \multicolumn{5}{|l|}{ TBili (mg/dl) } \\
\hline Starting & 0.4 & 0.4 & 0.4 & 0.430 \\
\hline Ending & 0.4 & 0.4 & 0.4 & 0.366 \\
\hline
\end{tabular}

${ }^{a} \mathrm{ALT}$, alanine transaminase; AlkPhos, alkaline phosphatase; $\mathrm{AST}$, aspartate transaminase; $\mathrm{CL}_{\mathrm{CR}}$, $\mathrm{creatinine}$ clearance; HgB, hemoglobin; Plt, platelets; TBili, total bilirubin.

bp value $<0.05$

$c P$ value $<0.001$

(0.001) did persist in the ABLC group after treatment cessation but did not persist not in the $\mathrm{L}-\mathrm{AmB}$ group ( $\mathrm{SCR} P=0.760, \mathrm{CrCl} P=0.969$ ). More studies and longer follow-up is needed to determine if these differences are clinically significant.

There was also a minor, but statistically significant, decrease in hemoglobin seen in both male and female ABLC patients, but not in L-AmB patients. Although there is a lack of data within the literature concerning lipid-based amphotericin B formulations and their effects on hemoglobin, amphotericin B deoxycholate has been shown to directly suppress erythropoietin production, resulting in decreased hemoglobin levels $(26,27)$. Neither iron studies nor other potential explanations for decreased hemoglobin levels were investigated further. The decrease in hemoglobin and impaired renal function after discontinuation in the ABLC group may suggest ABLC-related vasoconstriction and renal tubular cell toxicity, which may be irreversible $(28,29)$. There were no other significant changes in routinely monitored laboratory values, such as bilirubin, which had previously been reported in the literature $(20-22,24,25)$. 
TABLE 5 Follow-up renal function

\begin{tabular}{llll}
\hline & \multicolumn{1}{l}{ Time } & & \\
\cline { 2 - 3 } Assay & Start of treatment & End of treatment & $P$ value \\
\hline Serum creatinine $(\mathrm{mg} / \mathrm{dl})$ & & 1.01 & 0.009 \\
$\quad$ Amphotericin B lipid complex & 0.86 & 1.25 & 0.760 \\
$\quad$ Liposomal amphotericin B & 1.20 & & \\
& & 86.3 & 0.001 \\
Creatinine clearance (units/liter) & 102.4 & 77.1 & 0.969 \\
$\quad$ Amphotericin B lipid complex & 77.3 & & \\
$\quad$ Liposomal amphotericin B & &
\end{tabular}

Limitations. This study was a retrospective chart review and is subject to the inherent limitations of such a study design. The lack of blinding and the role of selection bias may be considered a weakness of the study, as those with chronic kidney disease, and perhaps those with more severe baseline disease, appear to have preferentially been given L-AmB. Patients were identified through outpatient registries, and those with acute disease were therefore not included in the study. Most of the patients in our study had pulmonary coccidioidomycosis, but due to the retrospective nature of our study, we were unable to consistently categorize lung involvements, such as severe primary pulmonary, mild pulmonary incidental to more serious disseminated infection, diffuse reticulonodular pulmonary indicative of fungemia, or chronic fibrocavitary infections. We were also therefore not able to clarify response rates between these subcategories. Lastly, we were unable to completely evaluate patients using the Mycosis Study Group scoring system, as follow-up radiology evidence was neither consistently available nor quantified according to the MSG scoring system, and repeat cultures were not collected due to the invasive nature of specimen collection.

Conclusion. This was the first descriptive study of lipid-based amphotericin B therapy in severe coccidioidomycosis patients. All previous studies involving amphotericin $B$ and coccidioidomycosis have been limited to either the conventional deoxycholate formulation or were conducted in nonhuman animal models. Both amphotericin B lipid complex and liposomal amphotericin B were effective and well tolerated in severe coccidioidomycosis patients. A gap in the medical literature remains for treating severe coccidioidomycosis patients, and comparative studies of lipid-based amphotericin B, intravenous triazole therapy, and oral triazole therapy in these patients is needed. Questions about the effects of ABLC and L-AmB on kidney function persist. Clinicians treating those with baseline kidney dysfunction may prefer to use liposomal amphotericin B instead of amphotericin B lipid complex. Prospective studies need to be conducted to evaluate the differences between the lipid-based amphotericin B formulations.

\section{MATERIALS AND METHODS}

Eligibility. This study was a retrospective chart review on patients identified through our outpatient infusion center records between January 2005 and December 2014. Inclusion criteria consisted of

TABLE 6 Reasons for switch of formulation or cessation

\begin{tabular}{lllll}
\hline & \multicolumn{3}{l}{ Treatment } & \\
\cline { 2 - 4 } Documented reason for cessation & Combined & $\begin{array}{l}\text { Amphotericin B } \\
\text { lipid complex }\end{array}$ & $\begin{array}{l}\text { Liposomal } \\
\text { amphotericin B }\end{array}$ & P value \\
\hline Total no. of subjects $(n[\%])$ & $69(100.0)$ & $37(56.6)$ & $32(43.4)$ & \\
Completion of therapy $(n[\%])$ & $35(50.7)$ & $17(45.9)$ & $18(56.3)$ & 0.553 \\
& & & & \\
Early discontinuation of therapy $(n[\%])$ & $33(47.8)$ & $19(51.4)$ & $14(43.8)$ & 0.117 \\
$\quad$ Failure or death & $5(7.2)$ & $1(2.7)$ & $4(12.5)$ & 0.007 \\
$\quad$ Acute kidney injury & $11(15.9)$ & $10(27.0)$ & $1(3.1)$ & 0.377 \\
$\quad$ Not tolerated & $4(5.8)$ & $3(8.1)$ & $1(3.1)$ & 0.350 \\
$\quad$ Noncompliance & $10(14.5)$ & $4(10.8)$ & $6(18.9)$ & 0.471 \\
$\quad$ Treatment burden & $3(4.3)$ & $1(2.7)$ & $2(6.3)$ & \\
Current $(n$ [\%]) & $1(1.4)$ & $1(2.7)$ & $0(0.0)$ & \\
\hline
\end{tabular}


receiving lipid-based amphotericin B therapy as either amphotericin B lipid complex (ABLC) (Abelcet) or liposomal amphotericin B (L-AmB) (AmBisome) at Kern Medical (KM) outpatient infusion center for the treatment of coccidioidomycosis, having baseline medical records and laboratory assessment prior to initiation of therapy and either one outpatient follow-up for assessment of disease progression (in the form of an infectious disease clinic visit with CF antibody titer and laboratory blood work) or an adverse effect requiring drug discontinuation prior to such a follow-up assessment. All patients received lipid-based amphotericin at the standard dose of $5 \mathrm{mg} / \mathrm{kg}$. Exclusion criteria consisted of age less than 18 years old, meningeal involvement, pregnancy, and patients lost to follow-up after initial assessment.

Assessment. A monitoring form was completed for each patient who met inclusion criteria. The form included demographics, comorbidities, site(s) of coccidioidomycosis infection, radiologic information, culture results, symptoms before and after treatment, type of lipid-based amphotericin B product received, number of weeks of treatment, baseline and end-of-treatment laboratory values, and physiciandocumented reason for discontinuation of lipid-based amphotericin B. Repeat serum creatinine (SCR) was also recorded after discontinuation for at least a period of 1 month and up to 1 year. All serum creatinine measurements were also analyzed using creatinine clearance $(\mathrm{CrCl})$, as determined by the Cockcroft-Gault equation. Follow-up $\mathrm{CrCl}$ was assessed at 1 month post amphotericin cessation or at the first available follow-up within 1 year. Pretreatment regimens for lipid-based amphotericin B included normal saline with or without potassium and/or magnesium, acetaminophen, diphenhydramine, and metoclopramide as needed, but premedications were not included in the analysis.

In lieu of MSG scoring, which was not possible in this retrospective study because of incomplete studies at the conclusion of treatment, we compared the numbers of symptoms and the difference in the coccidioidal CF titers before and at the conclusion of treatment to evaluate the success of response. Symptoms and CF titers were scored as per conventional MSG scoring and were combined into a cumulative score, which we titled the modified MSG score (mMSG).

Statistical analysis. The primary outcome was treatment success; secondary outcomes included physician-documented reason for amphotericin discontinuation and changes in laboratory organ function tests. All changes in lipid-based amphotericin B therapy were recorded and analyzed in terms of reasons requiring treatment discontinuation. Change of formulation was considered treatment failure. For comparisons between the two lipid-based amphotericin B groups, Pearson's chi-square tests or Fisher's exact chi-square tests were used for categorical variables when appropriate, and Mann-Whitney $\mathrm{U}$ tests were used for both continuous and discrete ordinal variables. Comparisons within variables from start to end of therapy with the two lipid-based amphotericin B groups were analyzed using Wilcoxon signed-rank tests. All analyses were conducted using STATA version 12.0 (StataCorp LP, College Station, TX).

\section{ACKNOWLEDGMENT}

We thank Jeff Jolliff for his assistance and help in this study.

\section{REFERENCES}

1. Galgiani JN, Ampel NM, Blair JE, Catanzaro A, Geertsma F, Hoover SE, Johnson RH, Kusne S, Lisse J, MacDonald JD, Meyerson SL, Raksin PB, Siever J, Stevens DA, Sunenshine R, Theodore N. 2016. Executive summary: 2016 Infectious Diseases Society of America (IDSA) clinical practice guideline for the treatment of coccidioidomycosis. Clin Infect Dis 63:717-722. https://doi.org/10.1093/cid/ciw538.

2. Cole GT, Hung C-Y, Sanderson SD, Hurtgen BJ, Wüthrich M, Klein BS, Deepe GS, Ostroff GR, Levitz SM. 2013. Novel strategies to enhance vaccine immunity against coccidioidomycosis. PLoS Pathog 9:e1003768.

3. Brown J, Benedict K, Park BJ, Thompson GR. 2013. Coccidioidomycosis: epidemiology. Clin Epidemiol 5:185-197. https://doi.org/10.2147/CLEP .S34434.

4. Lee C-Y, Thompson GR, Hastey CJ, Hodge GC, Lunetta JM, Pappagianis D, Heinrich V. 2015. Coccidioides endospores and spherules draw strong chemotactic, adhesive, and phagocytic responses by individual human neutrophils. PLoS One 10:e0129522. https://doi .org/10.1371/journal.pone.0129522.

5. Stevens DA. 1995. Coccidioidomycosis. N Engl J Med 332:1077-1082. https://doi.org/10.1056/NEJM199504203321607.

6. Chiller TM, Galgiani JN, Stevens DA. 2003. Coccidioidomycosis. Infect Dis Clin North Am 17:41-57. https://doi.org/10.1016/S0891-5520(02)00040-5.

7. Smith CE. 1940. Epidemiology of acute coccidioidomycosis with erythema nodosum ("San Joaquin" or "valley fever"). Am J Public Health Nations Health 30:600-611. https://doi.org/10.2105/AJPH.30.6.600.

8. Wheeler C, Lucas KD, Mohle-Boetani JC. 2015. Rates and risk factors for coccidioidomycosis among prison inmates, California, USA, 2011. Emerg Infect Dis 21:70-75. https://doi.org/10.3201/eid2101.140836.

9. Sondermeyer G, Lee L, Gilliss D, Tabnak F, Vugia D. 2013. Coccidioidomycosis-associated hospitalizations, California, U S A,
2000-2011. Emerg Infect Dis 19:1590-1597. https://doi.org/10.3201/ eid1910.130427.

10. Mathisen G, Shelub A, Truong J, Wigen C. 2010. Coccidioidal meningitis: clinical presentation and management in the fluconazole era. Medicine (Baltimore) 89:251-284. https://doi.org/10.1097/MD.0b013e3181f378a8.

11. Stewart ER, Eldridge ML, McHardy I, Cohen SH, Thompson GR. 2018. Liposomal amphotericin $B$ as monotherapy in relapsed coccidioidal meningitis. Mycopathologia. https://doi.org/10.1007/s11046-017-0240-7.

12. Segal BH, Herbrecht R, Stevens DA, Ostrosky-Zeichner L, Sobel J, Viscoli C, Walsh TJ, Maertens J, Patterson TF, Perfect JR, Dupont B, Wingard JR, Calandra T, Kauffman CA, Graybill JR, Baden LR, Pappas PG, Bennett JE, Kontoyiannis DP, Cordonnier C, Viviani MA, Bille J, Almyroudis NG, Wheat LJ, Graninger W, Bow EJ, Holland SM, Kullberg B-J, Dismukes WE, De Pauw BE. 2008. Defining responses to therapy and study outcomes in clinical trials of invasive fungal diseases: Mycoses Study Group and European Organization for Research and Treatment of Cancer consensus criteria. Clin Infect Dis 47:674-683. https://doi.org/10.1086/590566.

13. Johnson RH, Einstein HE. 2007. Amphotericin B and coccidioidomycosis. Ann N Y Acad Sci 1111:434-441. https://doi.org/10.1196/annals.1406.019.

14. Ostrosky-Zeichner L, Marr KA, Rex JH, Cohen SH. 2003. Amphotericin B: time for a new "gold standard." Clin Infect Dis 37:415-425. https://doi .org/10.1086/376634.

15. González GM, Tijerina R, Sutton DA, Graybill JR, Rinaldi MG. 2002. In vitro activities of free and lipid formulations of amphotericin $B$ and nystatin against clinical isolates of Coccidioides immitis at various saprobic stages. Antimicrob Agents Chemother 46:1583-1585. https://doi.org/10.1128/ AAC.46.5.1583-1585.2002.

16. Antony S, Dominguez DC, Sotelo E. 2003. Use of liposomal amphotericin $B$ in the treatment of disseminated coccidioidomycosis. J Natl Med Assoc 95:982-985. 
17. González GM, Tijerina R, Najvar LK, Bocanegra R, Rinaldi MG, Graybill JR 2004. Efficacies of amphotericin B (AMB) lipid complex, AMB colloidal dispersion, liposomal $A M B$, and conventional $A M B$ in treatment of murine coccidioidomycosis. Antimicrob Agents Chemother 48:2140-2143. https://doi.org/10.1128/AAC.48.6.2140-2143.2004.

18. Clemons KV, Capilla J, Sobel RA, Martinez M, Tong A-J, Stevens DA. 2009. Comparative efficacies of lipid-complexed amphotericin $B$ and liposomal amphotericin B against coccidioidal meningitis in rabbits. Antimicrob Agents Chemother 53:1858-1862. https://doi .org/10.1128/AAC.01538-08.

19. Wingard JR. 1997. Efficacy of amphotericin B lipid complex injection $(A B L C)$ in bone marrow transplant recipients with life-threatening systemic mycoses. Bone Marrow Transplant 19:343-347. https://doi.org/10 .1038/sj.bmt.1700664.

20. Fleming RV, Kantarjian HM, Husni R, Rolston K, Lim J, Raad I, Pierce S, Cortes J, Estey E. 2001. Comparison of amphotericin B lipid complex (ABLC) vs. ambisome in the treatment of suspected or documented fungal infections in patients with leukemia. Leuk Lymphoma 40: 511-520. https://doi.org/10.3109/10428190109097650.

21. Hamill RJ. 2013. Amphotericin B formulations: a comparative review of efficacy and toxicity. Drugs 73:919-934. https://doi.org/10.1007/s40265 -013-0069-4.

22. Wingard JR, White MH, Anaissie E, Raffalli J, Goodman J, Arrieta A; L Amph/ABLC Collaborative Study Group 2000. A randomized, doubleblind comparative trial evaluating the safety of liposomal amphotericin $B$ versus amphotericin $B$ lipid complex in the empirical treatment of febrile neutropenia. Clin Infect Dis 31: 1155-1163. https://doi.org/10 $.1086 / 317451$.
23. Walsh TJ, Finberg RW, Arndt C, Hiemenz J, Schwartz C, Bodensteiner D, Pappas P, Seibel N, Greenberg RN, Dummer S, Schuster M, Holcenberg JS; National Institute of Allergy and Infectious Diseases Mycoses Study Group. 1999. Liposomal amphotericin B for empirical therapy in patients with persistent fever and neutropenia. $\mathrm{N}$ Engl J Med 340:764-771.

24. Safdar A, Ma J, Saliba F, Dupont B, Wingard JR, Hachem RY, Mattiuzzi GN, Chandrasekar PH, Kontoyiannis DP, Rolston KV, Walsh TJ, Champlin RE, Raad II. 2010. Drug-induced nephrotoxicity caused by amphotericin B lipid complex and liposomal amphotericin B: a review and meta-analysis. Medicine (Baltimore) 89:236-244. https://doi.org/ 10.1097/MD.0b013e3181e9441b.

25. Girois SB, Chapuis F, Decullier E, Revol BGP. 2006. Adverse effects of antifungal therapies in invasive fungal infections: review and metaanalysis. Eur J Clin Microbiol Infect Dis 25:138-149. https://doi.org/10 .1007/s10096-005-0080-0.

26. Brandriss MW, Wolff SM, Moores R, Stohlman F. 1964. Anemia induced by amphotericin B. JAMA 189:663-666. https://doi.org/10 .1001/jama.1964.03070090013003.

27. Lin AC, Goldwasser E, Bernard EM, Chapman SW. 1990. Amphotericin B blunts erythropoietin response to anemia. J Infect Dis 161:348-351. https://doi.org/10.1093/infdis/161.2.348.

28. Zager RA, Bredl CR, Schimpf BA. 1992. Direct amphotericin B-mediated tubular toxicity: assessments of selected cytoprotective agents. Kidney Int 41:1588-1594. https://doi.org/10.1038/ki.1992.229.

29. Heyman SN, Stillman IE, Brezis M, Epstein FH, Spokes K, Rosen S. 1993. Chronic amphotericin nephropathy: morphometric, electron microscopic, and functional studies. J Am Soc Nephrol 4:69-80. 